\title{
COMPARATIVE STUDIES OF INHIBITIVE EFFECTS OF DIAMINES ON CORROSION OF ALUMINIUM ALLOY IN PRESENCE OF ACID MEDIA
}

\author{
Shobha Bhaskara ${ }^{1}$, Sanaulla Pathapalya Fakrudeen ${ }^{2}$, \\ V. Bheema Raju ${ }^{1, \infty}$, H.C. Ananda Murthy ${ }^{3}$ and Anjanapura V. Raghu ${ }^{4}$ \\ ${ }^{1}$ Department of Chemistry, Dr. Ambedkar Institute of Technology, Affiliated Visvesvaraya \\ Technological University, Bangalore, India, 560056 \\ ${ }^{2}$ Department of Chemistry, HKBK College of Engineering, Affiliated Visvesvaraya \\ Technological University, Bangalore, India, 560045 \\ ${ }^{3}$ Department of Applied Chemistry, Adama Science and Technology University, \\ P.O Box 1888, Adama, Ethiopia \\ ${ }^{4}$ Department of Chemistry, Faculty of Engineering Technology, Jain Deemed-to-be University, \\ Bangalore, India, 560069 \\ Corresponding Author: rajuvb54@gmail.com
}

\begin{abstract}
The studies of inhibitive effects of 4,4'-diaminostilbene (DS) and 4,4'-diaminoazobenzene (DA) on the corrosion inhibition of AA2024 alloy in the presence of $1 \mathrm{M} \mathrm{HCl}$ were performed using Potentiodynamic Polarization (PDP), Electrochemical Impedance Spectroscopy (EIS) and Weight-loss methods. PDP study results indicate that DS and DA behave as cathodic inhibitors. Variation in EIS parameters indicates that DS and DA adsorb on AA2024 alloy surface resulting in the creation of some inhibitive layer. Weight-loss study indicates that inhibition efficiency of DS and DA increases with their concentration and varies with immersion time and temperature of the solution. SEM analysis of surface characteristics of samples of both inhibited and uninhibited alloys reveals that the alloy surface is smothered in the presence of an inhibitor.

Keywords: Aluminium Alloy, Corrosion Inhibitors, Diamines, Electrochemical Techniques

RASĀYAN J. Chem., Special Issue, 2021
\end{abstract}

\section{INTRODUCTION}

Of late, there has been a surge in the usage of aluminium alloys in various industries, particularly the aerospace and automobile industries. This is because of their properties like lower mass, density, greater strength and resistant to wear. AA2024 is one such important aluminium alloy mostly used in crafting industries, in particular the wing and body structures, because of the high strength provided by $\mathrm{Mg}, \mathrm{Cu}$ and Si present in the alloy. AA2024 alloy is inhomogeneous in nature due to inconsistent size distribution. The inhomogeneous distribution of copper in aluminium alloy generates intergranular and intermetallic particles such as $\mathrm{Al}_{2} \mathrm{Cu}$ and $\mathrm{Al}_{6}(\mathrm{CuMnFe}){ }^{1,2}$ These intermetallic particles dislodge and lead to pitting corrosion, a characteristic of AA2024 corrosion. ${ }^{3,4}$

Different kinds of literature indicate that several inhibitors have been studied so far for their ability to control the corrosion of AA2024 alloy in the presence of acidic and neutral chloride solutions.

Adsorbed layer formed by vanadates on AA2024-T3 in $0.5 \mathrm{M} \mathrm{NaCl}$ helps in corrosion inhibition. ${ }^{5}$ Silicate provides strong anodic inhibition in high alkaline conditions at a threshold concentration of $0.01 \mathrm{M}^{6}$ Corrosion protection of pure aluminium alloy in neutral $\mathrm{NaCl}$ in the presence of inorganic salts like $\mathrm{Ce}$ (III) chloride, $\mathrm{Ce}(\mathrm{III})$ nitrate, $\mathrm{Ce}$ (III) acetate and $\mathrm{Ce}(\mathrm{IV})$ sulphate, and cerium malate and cerium dibutyl phosphate have been reported. ${ }^{7-10}$ Inhibiting effects of several organic compounds like benzotriazole, $\quad p$-aminoacetophenone, 8-hydroxylquinoline, 2-mercaptobenzothiazole, 2-(4(diethylamino)-2-hydroxybenzyledene) hydrazine carboamide, azole derivatives, sodium dodecyl benzene sulfonate, thiosemicarbazone derivatives and 1-pyrrolidine dithiocarbamate on the corrosion of AA2024 alloy in neutral chloride solutions have been investigated. ${ }^{11-26}$

Rasayan J. Chem., 72-82, Special Issue (2021)

http://doi.org/10.31788/RJC.2021.1456561

This work is licensed under a CC BY 4.0 license. 
The inhibitor efficiency of 2-(4-(diethylamino)-2-hydroxybenzyledene) hydrazine carboamide on AA2024-T3 in $0.5 \mathrm{M} \mathrm{HCl}$ was found to increase with along with its concentration. ${ }^{27}$ Properties of inorganic inhibitors like potassium permanganate have been studied on AA2024 anodized in sulphuric acid. $^{28}$ Inhibitive effects of eco-friendly extracts of linum usitatissimum seeds on the corrosion of AA2024 alloy immersed in $\mathrm{NaCl}$ solution have been studied. ${ }^{29}$ Some organic inhibitors like piperidin-4one and $\mathrm{Ce}^{4+}$ have been studied for their corrosion inhibition properties on aluminium. ${ }^{30}$ However, there is no significant study undertaken on organic inhibitors in acidic media, specifically the diamine derivatives. The AA2024 alloy is susceptible to severe corrosion in acid media. $\mathrm{HCl}$ is widely used for the alloy's electrochemical etching. As the dissolution rate of AA2024 in $\mathrm{HCl}$ is very high, it is necessary to avoid its dissolution by adding inhibitors as additives in the etching media. Organic inhibitors have the ability to control the corrosion in metal alloys by getting adsorbed and forming an insoluble layer on metal alloy surface due to chemisorption (formation of coordination bonds with atoms or ions) and physisorption (electrostatic interaction between metal and inhibitors). Electronegative group atoms (N, O, P, and S) found in inhibitor molecules help in strong bond formation on metal surface. ${ }^{31}$

Current work is aimed at investigating the inhibitive effect of 4-diaminostilbene (DS) and 4,4diaminoazobenzene (DA) on corrosion of AA2024 alloy in the presence of $1 \mathrm{M} \mathrm{HCl}$ using PDP, EIS and weight-loss methods.

\section{Test Specimens and Solution}

\section{EXPERIMENTAL}

AA2024 alloy was procured from M/s. Fenfee Metals, Bengaluru, in the form of ingots. It was melted and molded into 26-mm diameter and 170-mm length using the Gravity Die casting method at Metallurgical Lab, Chemistry Department, HKBK College of Engineering, Bengaluru. The alloy was examined using Optical Emission Spectrometry (as per IS: 7658) for its chemical composition at CMTI Lab, Bengaluru. The composition was found to be within the range of ASTM specifications as shown in Fig.-1.

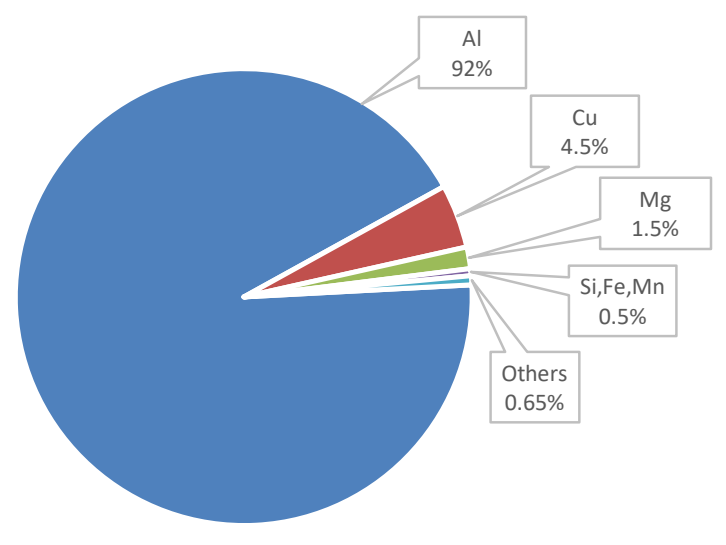

Fig.-1: AA 2024 Composition

For conducting the weight loss experiments, the test specimen rods were cut into cylindrical discs using the abrasive cutting wheel, each measuring a height of $20 \mathrm{~mm}$ and diameter of $24 \mathrm{~mm}$ and having a 20 $\mathrm{mm}$ mounting hole at the centre. These specimen rods were molded within cold set acrylic resin, leaving $1.0 \mathrm{~cm}^{2}$ area exposed. Before each experiment, the electrodes underwent abrasion by emery papers of various grades ranging from 6 to 12 hundred, double distil water washing, acetone degreasing and finally drying at $353 \pm 1 \mathrm{~K}$ for over half-hour in a thermostatic electric oven. Before every use, they were retained in a moisture-free desiccator. Stock solutions of diamines were prepared in $1 \mathrm{M} \mathrm{HCl}$ that was used as a corrosive medium.

\section{Diamine Inhibitors}

Diamines DS and DA were prepared in accordance with the method used by Hossein Naeimi and Arash Heidarnezhad..$^{32}$ By condensing the corresponding aromatic aldehydes with each of the diamines, a series 
RASĀYAN J.Chem.

72-82 | Special Issue | 2021

of diamines was prepared. Only analytical grade reagents purchased from Sigma Aldrich were used. FTIR and ${ }^{1} \mathrm{H}$ NMR spectral studies confirmed the identity of the product, along with melting points. Fig.2(a) and 2(b) depict the molecular structures of DS and DA.

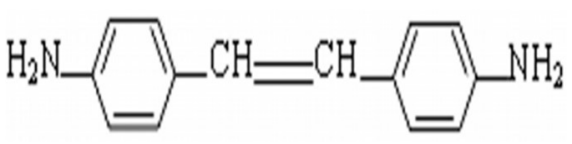

(a)

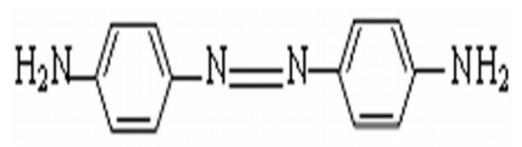

(b)

Fig.-2: (a) 4,4'-diaminostilbene (DS); (b) 4,4'-diaminoazobenzene (DA)

\section{Weight Loss Measurements}

These were performed as per ASTM G31-72(2004) method $^{33}$ under different parameters like specimen immersion duration, the temperature of the solution, the concentration of inhibitor and acid. Before each experiment, the following cleaning actions were performed:

- Abrade the electrodes using emery papers (Grades 600, 800, and 1200).

- Wash the electrodes using double distilled water.

- Degrease the electrodes using acetone.

- Dry the electrodes at $80^{\circ} \mathrm{C}$ for over half-hour in a thermostatic electric oven.

- Store the electrodes in a moisture-free desiccator (before using them again).

The corrosive solution was added to a glass bottle and was strapped with a condenser. This solution was in excess to avoid any changes in its corrosion intensity, which might have been caused by means of corrosive constituents being exhausted or by being deposited, which might affect further corrosion.

Before placing the specimen in the solution, it was weighed on Shimadzu AY220 electronic analytical weighing balance. After some noted time, it was washed under running water and was placed in $70 \%$ $\mathrm{HNO}_{3}$ for 3 minutes. It was gently rubbed with a nylon brush to remove the corrosion product from the alloy surface. Next, it was dried at $353 \mathrm{~K}$ temperature. Next, it was weighed (up to $0.1 \mathrm{mg}$ accuracy) and weight loss was noted down and studied using a constant temperature bath.

This procedure was followed for measuring weight loss in $100 \mathrm{~mL} \mathrm{HCl}$ solution $(1 \mathrm{M})$ with and without diamines presence (concentrations of 25 through $100 \mathrm{ppm}$ ) and at various temperatures (303 through $333 \pm 1 \mathrm{~K})$ and for different exposure periods (2, 4, 6, and 8 hours), all in triplicates.

Corrosion rate (CR) was calculated using weight loss values (W) measured in g, density (D) in $\mathrm{g} / \mathrm{cm}^{3}$, specimen exposed area (A) in $\mathrm{cm}^{2}$ and exposed time (T) in hours. $\mathrm{K}$ is a constant having the value $8.76 \mathrm{x}$ $10^{4}$.

$$
\mathrm{CR}=\frac{\mathrm{KW}}{\mathrm{DAT}}
$$

Inhibition efficiency percentage $\left(\mu_{\mathrm{WL}} \%\right)$ and degree of surface coverage $(\theta)$ were calculated as follows using weight loss values $\mathrm{W}_{0}$ (without inhibitors) and $\mathrm{W}_{\mathrm{i}}$ (with inhibitors):

$$
\begin{array}{r}
\mu_{\mathrm{WL}} \%=\frac{\mathrm{W}_{0}-\mathrm{W}_{\mathrm{i}}}{\mathrm{W}_{0}} \times 100 \\
\theta=\frac{\mathrm{W}_{0}-\mathrm{W}_{\mathrm{i}}}{\mathrm{W}_{0}}
\end{array}
$$

\section{Electrochemical Measurements}

The well-defined working electrode of $1 \mathrm{~cm}^{2}$ area was cleaned as explained under test specimen, materials and methods. The measurements were taken using a conventional 3-electrode glass Pyrex cell. Electrochemical measurements were conducted as per ASTM G3 - 14(2019) standard practice for conventions applicable to electrochemical measurements in corrosion testing.

\section{PDP Measurements}

Electrode potentials were polarized in the range -250 and $+250 \mathrm{mV}$ reference to OCP at $1 \mathrm{mV} / \mathrm{s}$ scan rate to obtain Tafel plots. Corrosion current densities (in the absence and presence of inhibitors - $\mathrm{I}_{\text {corr }}$ and $\mathrm{I}_{\text {corr }}^{\mathrm{o}}$ ) 
RASĀYAN J.Chem.

72-82| Special Issue | 2021

were obtained by extrapolating the linear segments related to anodic and cathodic curves from plots to corrosion potential $\left(\mathrm{E}_{\mathrm{corr}}\right)$. Inhibition efficiency $\left(\mu_{\mathrm{P}} \%\right)$ was calculated as follows:

\section{EIS Measurements}

$$
\mu_{\mathrm{p}} \%=\frac{\mathrm{I}_{\text {corr }}^{\mathrm{o}}-\mathrm{I}_{\text {corr }}}{\mathrm{I}_{\text {corr }}^{\mathrm{o}}} \times 100
$$

The experiments were conducted at $10 \mathrm{mV}$ peak-to-peak amplitude and AC signal at OCP @ $100 \mathrm{kHz}$ and $1.0 \mathrm{mHz}$ range, and impedance data was analysed using Nyquist plot. Data fitting for obtaining equivalent circuit model was performed using Echem software ZSimpWin v3.21. The inhibition efficiency $\left(\mu_{\text {Rct }} \%\right)$ was calculated as follows using charge transfer resistance $\mathrm{R}_{\text {ct }}^{\mathrm{i}}$ and $\mathrm{R}_{\text {ct }}{ }_{\text {(in presence and }}$ absence of inhibitor).

\section{SEM Analysis}

$$
\mu_{\mathrm{Rct}} \%=\frac{\mathrm{R}_{\mathrm{ct}}^{\mathrm{i}}-\mathrm{R}_{\mathrm{ct}}^{\mathrm{o}}}{\mathrm{R}_{\mathrm{ct}}^{\mathrm{i}}} \times 100
$$

The surface morphology of the corroded surface of Al alloy was studied for cases where inhibitors were added and where they were not. The specimen that was polished and specimen that was immersed in $\mathrm{HCl}$ (both having no inhibitors and having $100 \mathrm{ppm}$ diamines) were considered for the study.

\section{Weight Loss Study}

\section{RESULTS AND DISCUSSION}

Different measurements of weight loss $(\Delta \mathrm{w})$ of AA2024 alloy were taken at different conditions and the percentage of inhibitor efficiency $\left(\mu_{\mathrm{WL}} \%\right)$ was calculated to understand the corrosion rate (CR). The readings for an exposure time of two hrs, degree of surface coverage $(\theta)$, and other parameters are as shown in Table-1(a) and 1(b).

\begin{tabular}{c|c|c|c|c|c}
\multicolumn{7}{c}{ Table-1(a): Weight Loss Data using DS } \\
\hline $\begin{array}{c}\text { Temperature } \\
(\mathrm{K})\end{array}$ & $\begin{array}{c}\text { Concentration } \\
(\mathrm{ppm})\end{array}$ & $\begin{array}{c}\text { Weight Loss } \\
(\mathrm{mg})\end{array}$ & $\begin{array}{c}\text { C.R } \\
(\mathrm{mmpy})\end{array}$ & $\mu_{\mathrm{WL}} \%$ & $\theta$ \\
\hline \multirow{4}{*}{303} & 25 & 42.5 & 65.0 & 67 & 0.67 \\
\cline { 2 - 6 } & 50 & 37.3 & 57.1 & 71 & 0.71 \\
\cline { 2 - 6 } & 75 & 33.5 & 51.2 & 74 & 0.74 \\
\cline { 2 - 6 } & 100 & 29.6 & 45.3 & 77 & 0.77 \\
\hline \multirow{4}{*}{313} & 25 & 121.0 & 185.1 & 58 & 0.58 \\
\cline { 2 - 6 } & 50 & 112.3 & 171.9 & 61 & 0.61 \\
\cline { 2 - 6 } & 75 & 103.7 & 158.7 & 64 & 0.64 \\
\cline { 2 - 6 } & 100 & 89.3 & 136.6 & 69 & 0.69 \\
\cline { 2 - 6 } & 25 & 294.9 & 451.3 & 49 & 0.49 \\
\cline { 2 - 6 } & 50 & 281.6 & 430.9 & 53 & 0.53 \\
\cline { 2 - 6 } & 75 & 257.6 & 394.3 & 57 & 0.57 \\
\hline \multirow{4}{*}{333} & 100 & 227.7 & 348.4 & 62 & 0.62 \\
\cline { 2 - 6 } & 25 & 583.9 & 893.6 & 41 & 0.41 \\
\cline { 2 - 6 } & 75 & 593.3 & 908.0 & 45 & 0.45 \\
\cline { 2 - 6 } & 100 & 561.0 & 858.5 & 48 & 0.48 \\
\hline
\end{tabular}

\begin{tabular}{c|c|c|c|c|c}
\hline \multicolumn{7}{c}{} & \multicolumn{2}{c}{ Table-1(b): Weight Loss Data using DA } & \multicolumn{1}{c}{0.52} \\
\hline $\begin{array}{c}\text { Temperature } \\
(\mathrm{K})\end{array}$ & $\begin{array}{c}\text { Concentration } \\
(\mathrm{ppm})\end{array}$ & $\begin{array}{c}\text { Weight Loss } \\
(\mathrm{mg})\end{array}$ & $\begin{array}{c}\text { C.R } \\
(\mathrm{mmpy})\end{array}$ & $\mu_{\mathrm{WL}} \%$ & $\theta$ \\
\hline \multirow{3}{*}{303} & 25 & 41.2 & 63.0 & 72 & 0.72 \\
\cline { 2 - 6 } & 50 & 36.0 & 55.1 & 75 & 0.75 \\
\cline { 2 - 6 } & 75 & 29.6 & 45.3 & 78 & 0.78 \\
\cline { 2 - 6 } & 100 & 27.0 & 41.4 & 81 & 0.81 \\
\hline \multirow{2}{*}{313} & 25 & 115.2 & 176.3 & 63 & 0.63 \\
\cline { 2 - 6 } & 50 & 100.8 & 154.3 & 67 & 0.67 \\
\hline
\end{tabular}


RASĀYAN $J$. Chem.

72-82 | Special Issue | 2021

\begin{tabular}{l|c|c|c|c|c}
\hline \multirow{3}{*}{323} & 75 & 95.0 & 145.4 & 69 & 0.69 \\
\cline { 2 - 6 } & 100 & 83.5 & 127.8 & 73 & 0.73 \\
\cline { 2 - 6 } & 25 & 277.5 & 424.7 & 54 & 0.54 \\
\cline { 2 - 6 } & 50 & 254.4 & 389.3 & 57 & 0.57 \\
\cline { 2 - 6 } & 75 & 237.1 & 362.8 & 62 & 0.62 \\
\hline \multirow{3}{*}{333} & 100 & 202.4 & 309.7 & 67 & 0.67 \\
\cline { 2 - 6 } & 25 & 544.3 & 833.0 & 46 & 0.46 \\
\cline { 2 - 6 } & 50 & 504.7 & 772.5 & 50 & 0.50 \\
\cline { 2 - 6 } & 75 & 455.3 & 696.7 & 55 & 0.55 \\
\hline
\end{tabular}

\section{Effect of Inhibitor Concentration}

Higher values of inhibition efficiency for higher inhibitor concentration values are due to the persistent film being formed and inhibitor molecules covering a large area of the metal surface. Beyond $100 \mathrm{ppm}$ concentration, the inhibition efficiency remained almost constant, as shown in Fig.-3(a).

\section{Effect of Immersion Time}

The inhibition efficiency going down with immersion time increasing from two to eight hours, as shown in Fig.-3(b) is attributed to diamines getting desorbed which is a result of a lesser persistent film getting formed on the metal surface and cathodic reaction rate getting increased. ${ }^{34}$

\section{Effect of Temperature}

The inhibition efficiency going down with the rise in temperature, as shown in Fig.-3(c), is due to inhibitor molecules getting desorbed from the metal surface and aluminium getting dissolved at faster rates.

\section{Effect on Corrosion Rate}

The rate of corrosion of AA2024 decreases with an increase in inhibitor concentration through $25-100$ ppm for both DS and DA as shown in Fig.-3(d) and attributes to inhibitor forming a persistent protective layer on the alloy surface.

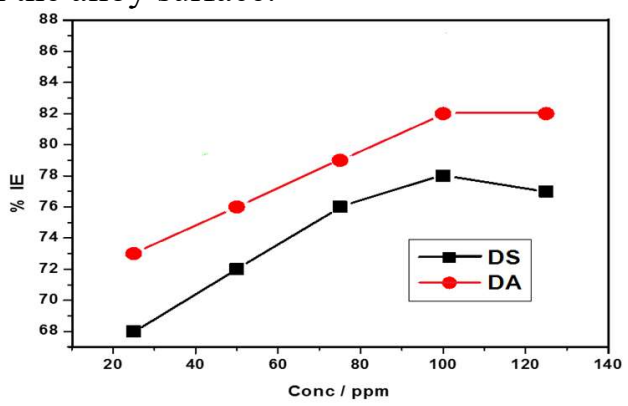

(a)

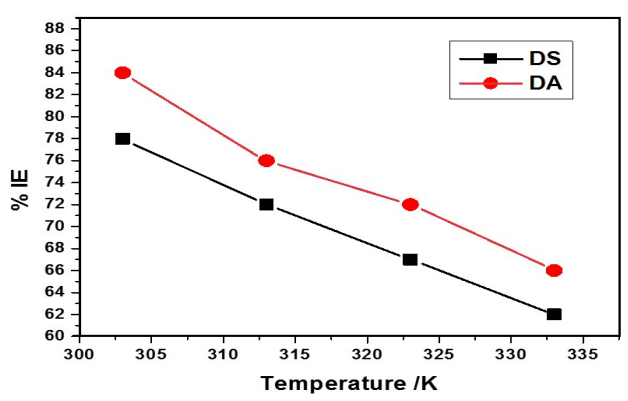

(c)

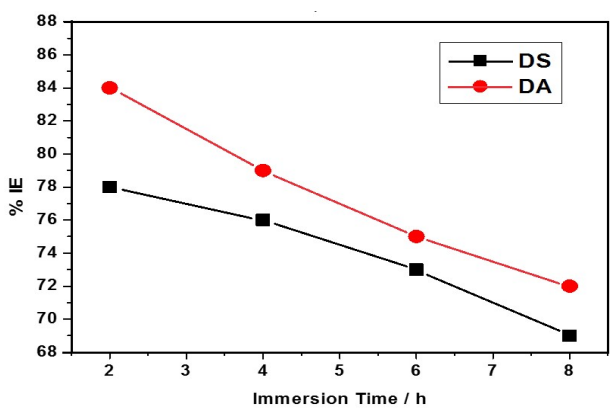

(b)

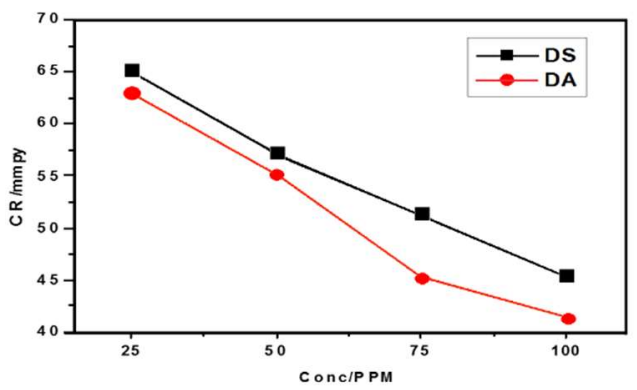

(d)

Fig.-3: Effect of (a) Inhibitor Concentration; (b) Immersion Time; (c) Temperature;

(d) Concentration vs Corrosion Rate 
RASĀYAN J.Chem.

72-82 | Special Issue | 2021

\section{PDP Measurements}

The experimental data were used to plot the PDP curves - Tafel plots (Fig.-4(a) for DS and Fig.-4(b) for DA). The corresponding PDP parameters like corrosion potential $\left(\mathrm{E}_{\text {corr }}\right)$, corrosion current density $\left(\mathrm{I}_{\text {corr }}\right)$, cathodic and anodic Tafel slopes $\left(b_{\mathrm{a}}\right.$ and $b_{\mathrm{c}}$ ) were derived from these Tafel plots and noted down as shown in Table-2. For each given concentration of DS and DA, the inhibition efficiency $\left(\mu_{\mathrm{p}} \%\right)$ of inhibitors was derived as in equation (4).

The PDP results show the curves to have shifted to lower current density when inhibitor concentration was increased, and show no major shift (within $85 \mathrm{mV}$ w.r.t $\mathrm{E}_{\text {corr }}$ of blank solution) in corrosion potential $\left(E_{\text {corr }}\right)$ values. This suggests the characteristics of mixed-type inhibitors. ${ }^{35,36}$ The PDP results also show the cathodic curves to have been more polarized. This suggests that the cathodic reduction rate is retarded and diamines were the influencers of cathodic reactions (compared to anodic) and hence suggests the characteristics of cathodic inhibitors, which could have occurred because of protonated diamine molecules being adsorbed on cathodic and anodic sites. ${ }^{37-40}$ DA was found to be more efficient than DS at different concentrations.

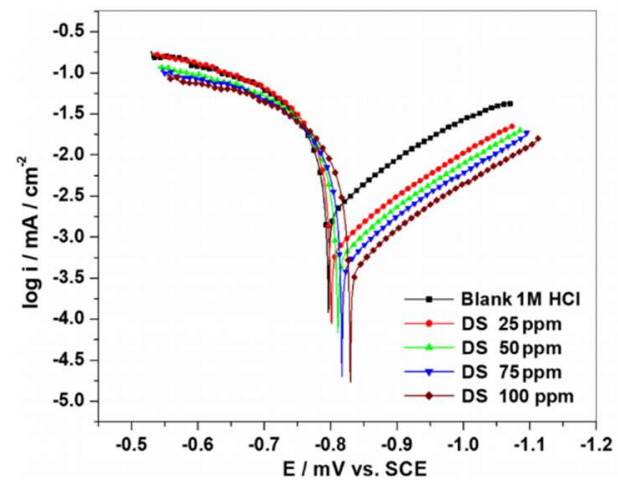

(a)

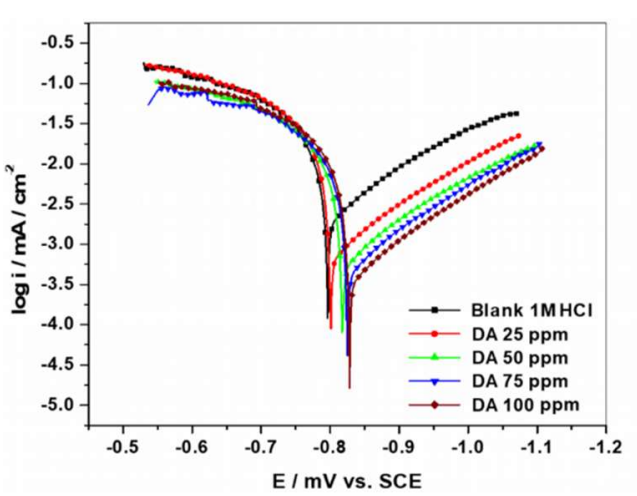

(b)

Fig.-4: Tafel Plots of (a) DS; (b) DA

Table-2: PDP Parameters

\begin{tabular}{c|c|c|c|c|c|c}
\hline Inhibitor & $\begin{array}{c}\text { Concentration } \\
(\mathrm{ppm})\end{array}$ & $\begin{array}{c}-\mathrm{E}_{\text {corr }} \\
(\mathrm{mV} \text { vs. SCE })\end{array}$ & $\begin{array}{c}\mathrm{i}_{\text {corr }} \\
\left(\mathrm{mA} \mathrm{cm}^{-2}\right)\end{array}$ & $\begin{array}{c}b_{\mathrm{c}} \\
\left(\mathrm{mV} \mathrm{dec}^{-1}\right)\end{array}$ & $\begin{array}{c}b_{\mathrm{a}} \\
\left(\mathrm{mV} \mathrm{dec}^{-1}\right)\end{array}$ & $\mu_{\mathrm{p}} \%$ \\
\hline \multirow{4}{*}{ DS } & 0 & 737 & 9.26 & 189 & 68 & --- \\
\cline { 2 - 7 } & 25 & 739 & 3.05 & 193 & 71 & 67 \\
\cline { 2 - 7 } & 50 & 745 & 2.68 & 195 & 77 & 71 \\
\cline { 2 - 7 } & 75 & 753 & 2.31 & 197 & 78 & 75 \\
\cline { 2 - 7 } & 100 & 758 & 2.13 & 198 & 85 & 77 \\
\hline \multirow{7}{*}{ DA } & 25 & 742 & 2.59 & 198 & 75 & 72 \\
\cline { 2 - 7 } & 50 & 747 & 2.32 & 201 & 77 & 75 \\
\cline { 2 - 7 } & 75 & 755 & 2.0 & 205 & 79 & 78 \\
\cline { 2 - 7 } & 100 & 759 & 1.66 & 210 & 86 & 82 \\
\hline
\end{tabular}

\section{EIS Measurements}

The experimental data were used to plot EIS - Nyquist plots (Fig.-5a and Fig.-5b). These show semicircles indicating the charge transfer to have been controlling the corrosion process. The curve looks similar, with a big capacitive loop at high frequencies and an inductive loop at low frequencies. Some researchers have also reported similar plots for $\mathrm{Al}$ in $\mathrm{HCl}^{41-47}$ In the plot, the semicircle having a centre under the real axis (behaviour termed as dispersing effect ${ }^{48,49}$ ) is the property of the solid electrode.

An equivalent circuit is depicted (Fig.-6) in which the elements like a solution, charge transfer and inductance resistance $\left(\mathrm{R}_{\mathrm{s}}, \mathrm{R}_{\mathrm{ct}}\right.$ and $\mathrm{R}_{\mathrm{L}}$, all measured in $\left.\Omega \mathrm{cm}^{-2}\right)$, inductance ( $\mathrm{L}$ measured in $\mathrm{H} \mathrm{cm} \mathrm{cm}^{-2}$ ) and constant phase element $\left(\mathrm{CPE}(\mathrm{Q})\right.$ measured in $\left.\mu \mathrm{F} \mathrm{cm}^{-2}\right)$ are fitted for simulating the measured impedance data of AA2024. 
RASĀYAN J. Chem.

72-82| Special Issue | 2021

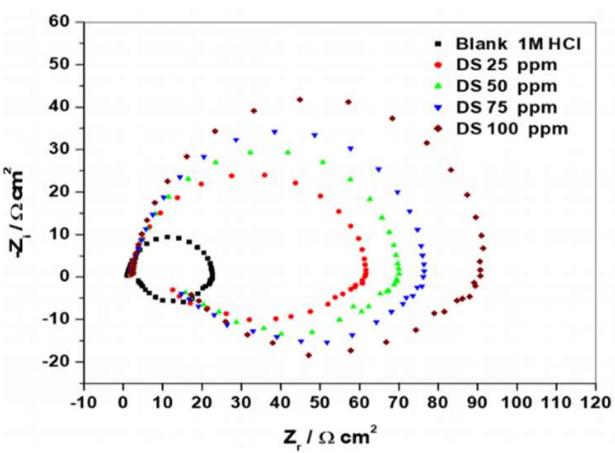

(a)

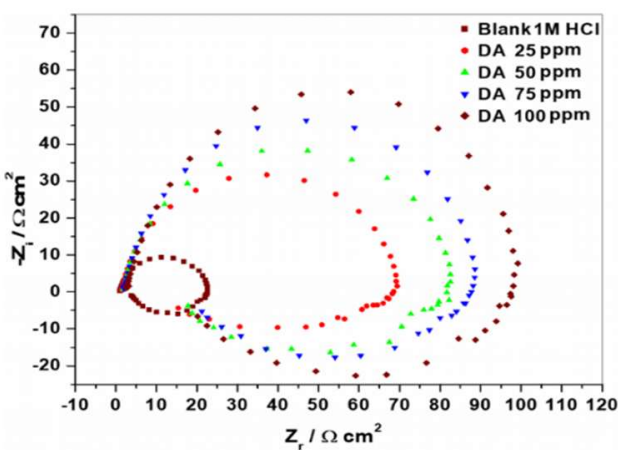

(b)

Fig.-5: Nyquist Plot of (a) DS; (b) DA;

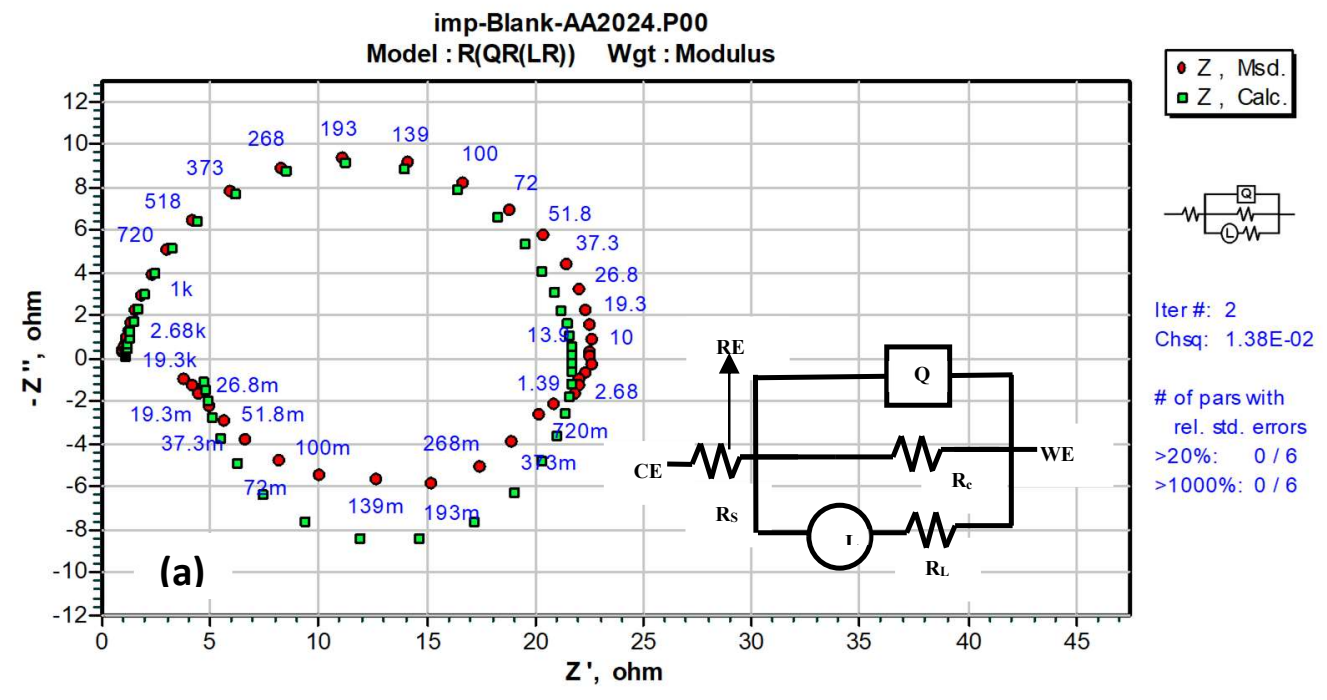

Fig.-6: Equivalent Circuit Model

CPE's impedance function is calculated using CPE magnitude and component $\left(\mathrm{Y}_{0}\right.$ and $\left.\mathrm{j}\right)$, angular frequency $(\omega)$ and surface morphology dependent value (n) as follows. ${ }^{50,51}$

$$
\mathrm{Z}_{\mathrm{CPE}}=\frac{1}{\left(\mathrm{Y}_{0} \mathrm{j} \omega\right)^{\mathrm{n}}}
$$

Double-layer capacitance $\left(\mathrm{C}_{\mathrm{dl}}\right)$ is derived as follows: ${ }^{52}$

$$
\mathrm{C}_{\mathrm{dl}}=\mathrm{Y}_{0}\left(\omega_{\max }\right)^{\mathrm{n}-1}
$$

The electrochemical impedance data are shown in Table-3. Depression in the impedance spectra is attributed to the non-homogeneous alloy surface. Assumption of $\left(\mathrm{R}_{\mathrm{c}}-\mathrm{C}_{\mathrm{dl}}\right)$ is a lose approximation, particularly where depressed semicircle behavior is shown, which is due to the electrodes' non-ideal behavior of capacitance. CPE, $\mathrm{C}_{\mathrm{dl}}$ and $\mu \mathrm{R}_{\mathrm{ct}} \%$ were evaluated by eqn.-5, 6 and $7 .^{53}$

The inhibition efficiency was deduced using $R_{c t}$ and $C_{d l}$ values. $R_{c t}$ of the inhibited system increased and $\mathrm{C}_{\mathrm{dl}}$ decreased when inhibitors were added, which was due to the adsorption of diamine molecules on metal. This forms a physical barrier and blocks either or both of the reactions, thereby reducing the metal reactivity, which might be because of changes in an electric double layer at a solution-metal electrode interface. The reduction in local dielectric constant and electric double layer thickening causes $\mathrm{C}_{\mathrm{dl}}$ to decrease. This indicates that diamine molecules inhibit corrosion by getting adsorbed on the metal-acid interface. Inhibition efficiency increasing along with its concentration was evident. This is in line with the PDP results. $\mathrm{R}_{\mathrm{ct}}$ and $\mathrm{C}_{\mathrm{dl}}$ values show that the diamines inhibit corrosion of AA2024 alloy more efficiently. Among them, 4,4-diaminoazobenzene (DA) is more efficient than 4,4-diaminostilbene (DS). 
RASĀYAN J.Chem.

72-82 | Special Issue | 2021

Table-3: EIS Data

\begin{tabular}{|c|c|c|c|c|c|c|c|c|c|c|}
\hline 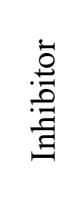 & 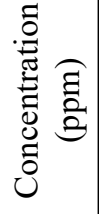 & 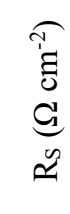 & 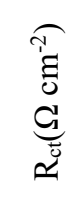 & 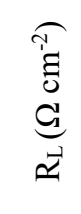 & & $\underbrace{\underset{N}{ \pm}}_{3}$ & 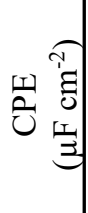 & $z$ & 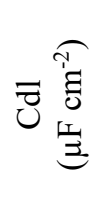 & 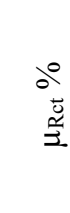 \\
\hline \multirow{5}{*}{ DS } & 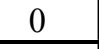 & 14 & 09 & 41 & 26.1 & 01 & 119 & & 7.0 & -1 \\
\hline & 25 & 17 & 27.2 & 13.3 & 99.1 & 19 & 69 & 1 & 49.9 & 66.9 \\
\hline & 50 & 1.21 & 32.3 & 22.5 & 109.5 & 22 & 56 & .9169 & 37.7 & 72.1 \\
\hline & 75 & 1.29 & 37.7 & 23.1 & 111.6 & 25 & 41 & 9282 & 29.1 & 76.1 \\
\hline & 100 & 1.38 & 39.8 & 25.2 & 125.1 & 31 & 33 & 0.9303 & 25.3 & 77.4 \\
\hline \multirow{4}{*}{ DA } & 25 & 1.23 & 33.2 & 16.9 & 119.3 & 23 & 52 & 205 & 35.6 & 72.9 \\
\hline & 50 & 1.39 & 38.1 & 21.3 & 135.0 & 27 & 38 & 0.9219 & 26.9 & 76.4 \\
\hline & $\overline{75}$ & 1.47 & 43.1 & 22,5 & 179.0 & 32 & 31 & 0.9287 & 22.1 & 79.1 \\
\hline & 100 & 1.52 & 53.3 & 39.1 & 199.6 & 35 & 27 & 0.9398 & 18.9 & 83.1 \\
\hline
\end{tabular}

\section{Mechanism of Inhibition}

The inhibitor molecules undergo protonation in highly acidic solutions and remain as protonated positive species. These protonated species adsorb on cathodic sites of alloy surface through electrostatic interaction and thereby decreasing the rate of cathodic reaction. The anions present in the corrosive solution assist in the inhibition process by organic compounds by getting adsorbed on alloy surfaces. Since the corrosive medium in this investigation is highly acidic and the alloy surface is positively charged, the negative $\mathrm{Cl}^{-}$anions get adsorbed onto the surface of the alloy that making the alloy surface negatively charged. As a result, the physisorption of positively charged protonated-inhibitor-compound molecules occurs on alloy surface interacting with $\mathrm{Cl}^{-}$ions that are adsorbed on alloy surface through electrostatic interaction. The negative charge centres of the inhibitor molecules that contain lone pair of electrons and $\pi$-electrons get involved in an interaction with anodic sites on the alloy surface, resulting in their adsorption. The neutral inhibitor molecules occupy the sites on the surface of alloy that is vacant through chemisorption by displacing the water molecules from the alloy surface and sharing electrons by nitrogen atoms. Inhibitor molecules existing in protonated form and the presence of negatively charged centres on the inhibitor molecules are also the reason for inhibitor molecules interacting mutually on the surface of the alloy.

In acidic solution, nitrogen atoms from inhibitor molecules may get adsorbed on cathodic sites of AA2024 alloy surface competing with $\mathrm{H}^{+}$ions. This is a result of organic compounds getting adsorbed via phenolic, amine and imine groups through the de-localized $\pi$-electrons of the phenolic group, amine and imine nitrogen. The inhibition efficiency of 4,4'-diaminoazobenzene (DA) was found to be higher than that of 4,4'-diaminostilbene (DS) due to the presence of more electronegative imine group $-\mathrm{N}=\mathrm{N}-$ in DA molecule. The probable adsorption mode of DS and DA is shown in Fig.-7(a) and 7(b).
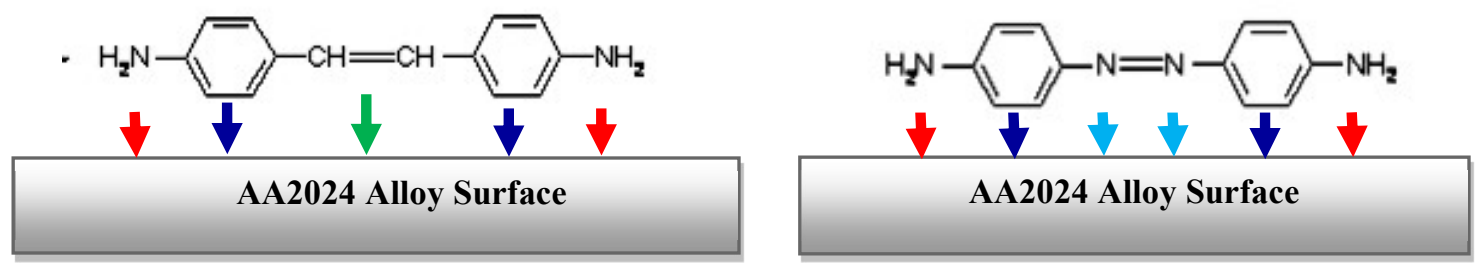

\section{SEM Analysis}

Fig.-7: Adsorption of (a) DS; (b) DA

Figure-8(a) and 8(b) show SEM images of polished AA2024 alloy with smooth surface and with rough surface (due to attack of $1 \mathrm{M} \mathrm{HCl}$ ), respectively. Figure-8(c) and (d) show SEM images of AA2024 alloy 
in the presence of DS and DA, respectively. It is noticed that the alloy surface gets damaged to a lesser extent in the presence of inhibitor compounds. The alloy surface is smoother and uniform in the case of DA than with DS. Thus, DA is concluded to be protecting AA2024 effectively than DS does in $1 \mathrm{M} \mathrm{HCl}$.

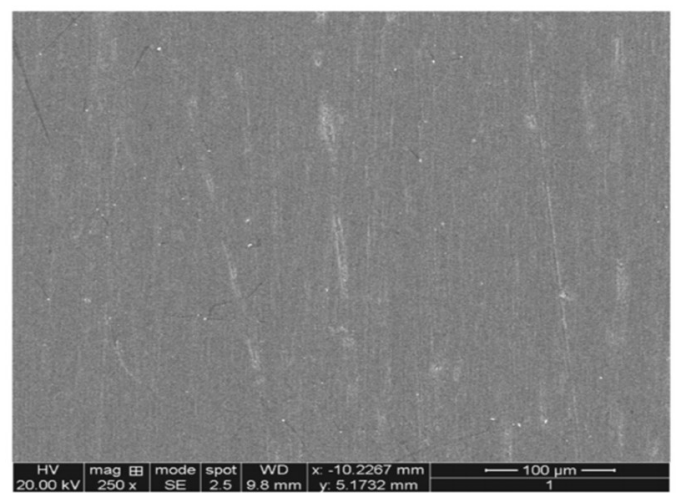

(a)

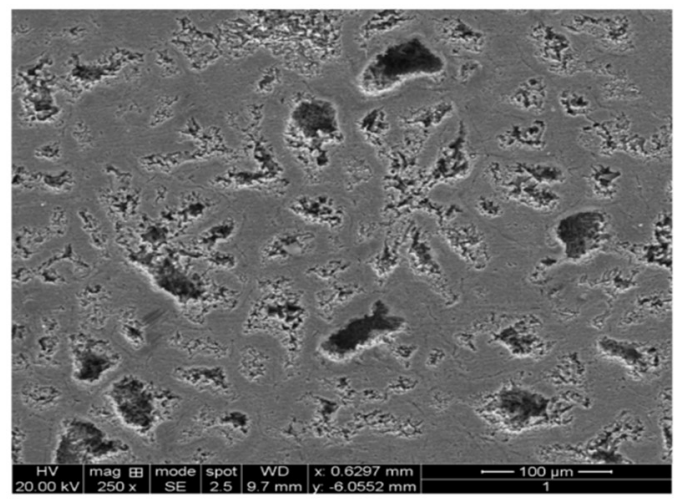

(c)

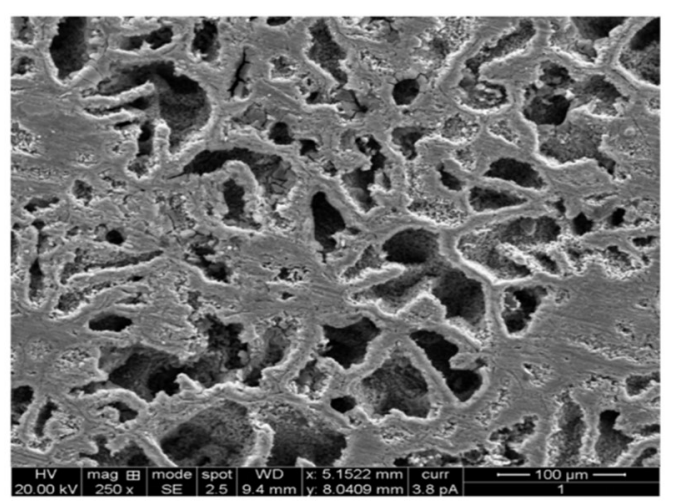

(b)

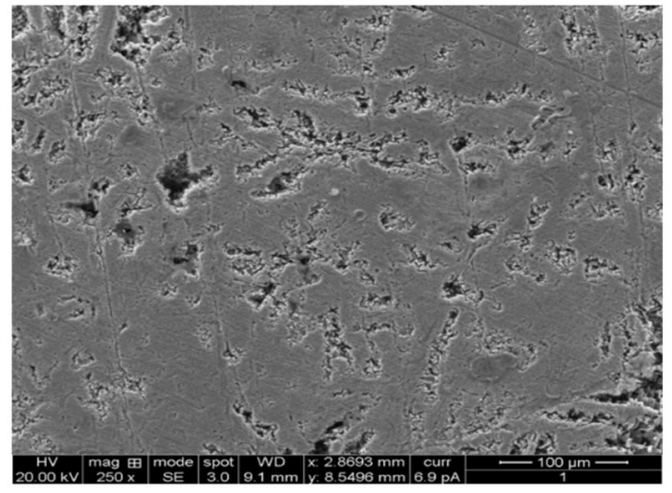

(d)

Fig.-8: SEM images (a) Polished alloy; (b) Rough surface with corrodent; (c) With DS; (d) With DA

\section{CONCLUSION}

The efficiency of DS and DA inhibitors increasing with their concentration is a result of the formation of a persistent film layer at higher concentrations. Their efficiency decreasing with an increase in time of exposure is due to the formation of the lesser persistent film. Their efficiency decreasing with an increase in temperature is due to inhibitor molecules getting desorbed at higher temperatures and dissolution rates. PDP studies show that DS and DA act as mixed-type inhibitors, but mainly as cathodic inhibitors. EIS studies show that values of $\mathrm{R}_{\mathrm{ct}}$ increase while that of $\mathrm{C}_{\mathrm{dl}}$ decrease with an increase in inhibitor concentration, which indicates inhibition to be happening purely due to surface adsorption of inhibitor. From SEM images, it is seen that smooth surfaces show up for inhibited alloy samples rather than for uninhibited ones, which is due to stable, protective barrier film getting formed on the alloy surface. Based on all these findings, it may be concluded that 4,4'-diaminostilbene (DS) and 4,4'-diaminoazobenzene (DA) effectively inhibit the corrosion of AA2024 alloy surface in $1 \mathrm{M} \mathrm{HCl}$.

\section{REFERENCES}

1. A.E. Hughes, R. Parvizi and M. Forsyth, Corrosion Reviews, 33(1-2), 1(2015), https://doi.org/10.1515/corrrev-2014-0039

2. T. Hashimoto, X. Zhang, X. Zhou and P. Skeldon, Corrosion Science, 103(1), 157(2016), https://doi.org/10.1016/j.corsci.2015.11.013

3. W. Zhang and G.S. Frankel, Electrochimica Acta, 48(9), 1193(2003), https://doi.org/10.1016/S00134686(02)00828-9

4. P. Leblanc and G.S. Frankel, Journal of The Electrochemical Society, 149(6), 239(2002), http://dx.doi.org/10.1149/1.1471546 
RASĀYAN J. Chem.

72-82 | Special Issue | 2021

5. M. Iannuzzi and G.S. Frankel, Corrosion Science, 49(5), 2371(2007), https://doi.org/10.1016/j.corsci.2006.10.027

6. O. Lopez-Garrity and G.S. Frankel, Electrochimica Acta, 130(1), 9(2014), https://doi.org/10.1016/j.electacta.2014.02.117

7. Peter Rodič and Ingrid Milošev, Journal of The Electrochemical Society, 163(3), 85(2016), https://www.doi.org/10.1149/2.0431603jes

8. L.B. Coelho, D. Cossement and M.G. Olivier, Corrosion Science, 130(1), 177(2018), http://dx.doi.org/10.1016/j.corsci.2017.11.004

9. Tianhui Hu, Hongwei Shi, Dongcen Hou and En-Hou Han, Applied Surface Science, 467-468(1), 1011(2019), http://dx.doi.org/10.1016/j.apsusc.2018.10.243

10. Daniel Ho, Narelle Brack, John Scully, Tracey Markley, Maria Forsyth and Bruce Hinton, Journal of The Electrochemical Society, 153(9), B392(2006), https://doi.org/10.1149/1.2217260

11. V. Sviatlana Lamaka, M.L. Zheludkevich, Kiryl Yasakau and M.F. Montemor, Electrochimica Acta, 52(25), 7231(2007), https://doi.org/10.1016/j.electacta.2007.05.058

12. Inime Ime Udoh, Hongwei Shi, Fuchum Liu and En-Hou Han, Journal of The Electrochemical Society, 166(6), 185(2019), http://dx.doi.org/10.1149/2.0621906jes

13. Isaline Recloux, Francesco Andreatta, Marie-Eve Druart, Leonardo Bertolucci Coelho, Cinzia Cepek, Damien Cossement, Lorenzo Fedrizzi and Marie-Georges Olivier, Journal of Alloys and Compounds, 735(1), 2512(2018), https://doi.org/10.1016/j.jallcom.2017.11.346

14. Husnu Gerengi, Moses M. Solomon, Mine Kurtay, Gözen Bereket, Kadir Gökşen and Mesut Yildiz, Journal of Adhesion Science and Technology, 32(2), 207(2018), https://doi.org/10.1080/01694243.2017.1350524

15. B.G. Prakashiah, A. Nityananda Shetty and B.E. Amitha Rani, Journal of The Minerals, Metals and Materials Series, 71(1), 4880(2019), https://doi.org/10.1007/s11837-019-03615-4

16. M.L Zheludkevich, K.A. Yasakau, S.K. Poznyak and M.G.S. Ferreira, Corrosion Science, 47(12), 3368(2005), http://dx.doi.org/10.1016/j.corsci.2005.05.040

17. Klodian Xhanari and Matjaž Finšgar, Coatings (MDPI), 9(6), 380(2019), https://doi.org/10.3390/coatings9060380

18. Yu Zuo, Biner Zhou and Yuming Tang, International Journal of Electrochemical Science, 12(1), 11137(2017), http://dx.doi.org/10.20964/2017.12.58

19. Grégory Boisier, Nicolas Portail and Nadine Pébère, Electrochimica Acta, 55(21), 6182(2010), http://dx.doi.org/10.1016/j.electacta.2009.10.080

20. B.W. Samuels, K. Sotoudeh and R.T. Foley, Corrosion, 37(2), 92(1981), https://doi.org/10.5006/1.3593852

21. Thomas Stimpfling, Pierre Vialat, Horst Hintze-Bruening, Viacheslav Shkirskiy, Patrick Keil, Polina Volovitch, Kevin Ogle and Fabrice Leroux, European Journal of Inorganic Chemistry, 2016(13), 2006(2016), http://dx.doi.org/10.1002/ejic.201501161

22. Xing Li, Bin Xiang, Xiu-li Zuo, Qin Wang and Zi-dong Wei, Journal of Materials Engineering and Performance, 20(2), 265(2011), http://dx.doi.org/10.1007/s11665-010-9680-7

23. B.G. Prakashaiah, D. Vinaya Kumara, A. Anup Pandith, A. Nityananda Shetty and B.E. Amitha Rani, Corrosion Science, 136(1), 326(2018), https://doi.org/10.1016/j.corsci.2018.03.021

24. W. Qafsaoui, M.W. Kendig, H. Perrot and H. Takenouti, Corrosion Science, 92(1), 245(2015), https://doi.org/10.1016/j.corsci.2014.12.011

25. K.A. Yasakau, M.L. Zheludkevich, O.V. Karavai, M.G.S. Ferreira, Progress in Organic Coatings, 63(3), 352(2008), https://doi.org/10.1016/j.porgcoat.2007.12.002

26. I.Z. Selim, A.A. Khedr and N.A. Ibrahim, Bulletin of Electrochemistry, 16(4), 186(2000)

27. B.G. Prakashiah, A. Nityananda Shetty and B.E. Amitha Rani, Surface Engineering and Applied Electrochemistry, 54(3), 286(2018), https://doi.org/10.3103/S1068375518030109

28. Maysam Mohammadi, Ali Yazdani, Farzad Mohammadi and Akram Alfantazi, Light Metals, 509(2013), https://doi.org/10.1007/978-3-319-65136-1_87 
RASĀYAN J. Chem.

72-82 | Special Issue | 2021

29. H. Elgahawi, M. Gobara and A. Baraka, Journal of Bio- and Tribo-Corrosion, 3(55), (2017), https://doi.org/10.1007/s40735-017-0116-x

30. K. Rathidevi, S. Jyothi, D. Jalajaa and S. Karthikeyan, Rasayan Journal of Chemistry, 12(2), 565(2019), http://dx.doi.org/10.31788/RJC.2019.1224098

31. T.G. Harvey, S.G. Hardin, A.E. Hughes and T.H. Muster, Corrosion Science, 53(6), 2184(2011), https://doi.org/10.1016/j.corsci.2011.02.040

32. Hossein Naeimi and Arash Heidarnezhad, Bulletin of the Chemical Society of Ethiopia, 29(1), 117(2015), https://doi.org/10.4314/BCSE.V29I1.10

33. Standard Practice for Laboratory Immersion Corrosion testing of Metal-ASTM G31-72-2004, https://www.astm.org/g0031-72r04.html

34. S. Haruyama and T. Tsuru, Corrosion Engineering, 27(11), 573(1978), https://doi.org/10.3323/jcorr1974.27.11 573

35. E.S. Ferreira, C. Giacomelli, F.C. Giacomelli and A. Spinelli, Materials Chemistry and Physics, 83(1), 129(2004), http://dx.doi.org/10.1016/j.matchemphys.2003.09.020

36. W.H. Li, Q. He, S.T. Zhang, C.L. Pei and B.R. Hou, Journal of Applied Electrochemistry, 38(3), 289(2008), http://dx.doi.org/10.1007/s10800-007-9437-7

37. A. Yurt, S. Ulutas and H. Dal, Applied Surface Science, 253(2), 919(2006), https://doi.org/10.1016/j.apsusc.2006.01.026

38. O. Olivares, N.V. Lihanova, B. Gomez, J. Navarrete, M.E. Lianos-Serrano, E. Arce and J.M. Hallen, Applied Surface Science, 252(8), 2894(2006), https://doi.org/10.1016/j.apsusc.2005.04.040

39. Sanaulla Pathapalya Fakrudeen, H.B. Lokesh, H.C. Ananda Murthy and V. Bheema Raju, IOSR Journal of Applied Chemistry, 5(2), 37(2012), http://dx.doi.org/10.9790/5736-0253747

40. Sanaulla Pathapalya Fakrudeen, H.C. Ananda Murthy and V. Bheema Raju, Journal of the Chilean Chemical Society, 57(4), 1364(2012), http://dx.doi.org/10.4067/S0717-97072012000400007

41. F.C. Burgess and S.G. Engle, Transactions of the American Electrochemical Society, 9(1), 199(1903)

42. W.H. Ailor, Engine Coolant Testing: State of the Art, ASTM, Philadelphia, p.134(1980), https://www.astm.org/stp705-eb.html

43. M.G. Fontana and N.D. Greene, Corrosion Engineering, McGraw-Hill, New York, p.43(1967)

44. M.G. Fontana, Corrosion Engineering, McGraw-Hill, New York, p3(1987)

45. D.A. Jones, Principles and prevention of corrosion, Prentice Hall, New Jersey, p.2(1996)

46. F.N. Spellar, Corrosion: causes and prevention- An Engineering Problem, McGraw-Hill, New York, p8(1935)

47. J.M. Smith and H.C. Van Hess, Introduction to Chemical Engineering Thermodynamics, Tata McGraw-Hill Co, New Delhi, p.1(1975)

48. M. Pourbiax, Atlas of Electrochemical Equilibria in Aqueous Solutions, National Association of Corrosion Engineers, Texas, p.644(1974)

49. J.A.V. Butler, Transactions of the Faraday Society, 19(1), 729(1924), https://doi.org/10.1039/TF9241900729

50. H.J.W. Lenderink, M.V.D. Linden and J.H.W. De Wit, Electrochimica Acta, 38(14), 1989(1993), https://doi.org/10.1016/0013-4686(93)80329-X

51. F. Mansfeld, C.H. Tsai, H. Shih and in: R.S. Munn (Ed.), Computer Modelling in Corrosion, ASTM, Philadelphia, p.86(1992)

52. C.H. Hsu and F. Mansfeld, Corrosion, 57(9), 747(2001), https://doi.org/10.5006/1.3280607

53. C. Wagner and W. Traud, Corrosion, 62(10), 843(2006), https://doi.org/10.5006/1.3279894

[RJC-6561/2021] 